\title{
ANALISIS PROBLEMATIKA MUTU PENDIDIKAN TINGKAT DASAR BERDASARKAN HASIL AKREDITASI DI KABUPATEN KUANTAN SINGINGI
}

\author{
Johan Andriesgo ${ }^{1}$, Haris Riadi' ${ }^{2}$, Joni Hendra $\mathrm{K}^{3}$ \\ ${ }_{1}^{1}$ Program Studi Manajemen Pendidikan Islam, STAIN Bengkalis, Riau, Indonesia \\ ${ }^{2}$ Program Studi Manajemen Pendidikan Islam, STAIN Bengkalis, Riau, Indonesia \\ ${ }^{3}$ Program Studi Manajemen Keuangan Syariah, STAIN Bengkalis, Riau, Indonesia \\ Email: andriesgo@yahoo.com ${ }^{1}$, harisriadi@kampusmelayu.ac.id ${ }^{2}$, joni_hendra77@yahoo.co.id ${ }^{3}$
}

DOI: http://doi.org/10.33650/al-tanzim.v4i2. 1099

\begin{tabular}{l|l|l} 
Received: April 2020 & Accepted: August 2020 & Published: September 2020
\end{tabular}

\begin{abstract}
:
This research aims to find out about the problems of education quality faced by SD / MI in Kuantan Singingi Regency based on the results of the 2019 accreditation. The research was revealed in 97 schools/madrasah at SD/MI. It was designed as a qualitative descriptive research. Data were collected through interview, observation, and documentation. The findings show that the problems faced by schools/madrasah based on the achievements of the accreditation results in 2019 are on fulfilling the standards of educators, education personnel, educational facilities and infrastructure standards. Fulfillment of the standards of educators and educational staff including those related to academic qualifications of educators, educators' certificates ownership, teachers' educational suitability background and their teaching staff adequacy. Whereas the standard of facilities and infrastructure are related to the completeness of facilities and infrastructure such as: teacher's room, library, UKS, circulation, canteen ownership, and learning aids.
\end{abstract}

Keywords: quality of education, elementary school, accreditation

\begin{abstract}
Abstrak:
Penelitian ini bertujuan untuk mengetahui tentang problematika mutu pendidikan yang dihadapi oleh SD/MI di Kabupaten Kuantan Singingi berdasarkan hasil akreditasi tahun 2019. Penelitian ini dilakukan terhadap 97 sekolah/madrasah tingkat SD/MI yang sekaligus menjadi sampel penelitian. Penelitian menggunakan penelitian kualitatif deskriptif. Teknik pengumpulan data dilakukan melalui wawancara, observasi dan dokumentasi. Hasil penelitian menunjukan bahwa problematika yang dihadapi sekolah/madrasah berdasarkan capaian hasil akreditasi tahun 2019 adalah pada pemenuhan standar pendidik dan tenaga kependidikan dan pemenuhan standar sarana dan prasarana. Pemenuhan standar pendidik dan tenaga kependidikan diantaranya terkait kualifikasi akademik tenaga pendidik, kepemilikan sertifikat pendidik, kesesuaian guru mengajar dengan latar belakang pendidikannya serta ketercukupan tenaga kependidikannya. Sedangkan pada standar sarana dan prasarana diantaranya terkait kelengkapan sarana dan prasarana seperti: ruang guru, perpustakaan, UKS, sirkulasi, kepemilikan kantin, dan alat peraga pembelajaran.
\end{abstract}

Kata Kunci: mutu pendidikan, sekolah dasar, akreditasi 


\section{PENDAHULUAN}

Dalam Undang-Undang Nomor 20 Tahun 2003 tentang Sistem Pendidikan Nasional dikatakan bahwa Pendidikan adalah usaha sadar dan terencana untuk mewujudkan suasana belajar dan proses pembelajaran agar peserta didik secara aktif mengembangkan potensi dirinya untuk memiliki kekuatan spiritual keagamaan pengendalian diri, kepribadian, kecerdasan, akhlak mulia, serta keterampilan yang diperlukan dirinya masyarakat, bangsa dan Negaranya.

Pendidikan itu sendiri tentunya bisa didapatkan melalui proses belajar, seorang manusia dapat belajar melalui pendidikan formal, non formal dan informal. Pendidikan formal akan didapatkan pada sekolah dengan berbagai tingkatan, baik pada tingkat Sekolah Dasar (SD)/ Madrasah Ibtidaiyah (MI), Sekolah Menengah Pertama (SMP)/ Madrasah Tsanawiyah (MTs) maupun Sekolah Menengah Atas (SMA)/ Sekolah Menengah Kejuruan (SMK)/ Madrasah Aliyah (MA). Untuk memberikan jaminan kepada masyarakat (peserta didik) tentang hak dan kewajiban warga Negara sesuai dengan pasal 5 ayat 1 Undang-Undang Nomor 20 Tahun 2003 tentang Sistem Pendidikan Nasional, setiap warga Negara mempunyai hak yang sama untuk memperoleh pendidikan yang bermutu.

Mutu merupakan kesesuaian dengan kebutuhan pasar (Agrawal, 2019; Dudin, et al., 2017). Mutu juga dimaknaisebagai kecocokan penggunaan produk (fitness for use) dan kesesuaian dengan yang disyaratkan (conformance to requirement) (Aarti, 2015; Sutarto, 2015). Mutu dapat juga dimaknai seberapa jauh barang atau jasa dapat memberikan kepuasan kepada pelanggan sesuai atau melampaui harapan-harapan pelanggan (Chairunnisa, 2016). Mutu sebagai keadaan yang sesuai dan melebihi harapan pelanggan hingga pelanggan memperoleh kepuasan (Komariah \& Engkoswara, 2017). Pendapat lain mengatakan bahwa mutu merupakan produk atau jasa sesuai dengan standar yang telah ditetapkan dan memuaskan pelanggan (Ariyani, 2015). Jika dikaitkan dengan pendidikan, dapat dikatakan bahwa mutu pendidikan merupakan derajat keunggulan sebuah lembaga pendidikan (Amir, 2015; Amai, 2018), yang mana lembaga pendidikan itu sendiri sudah sesuai atau melebihi standar, sesuai dengan harapan pelanggan, pihak-pihak terkait dan sesuai dengan yang dijanjikan (Satria, et al., 2019).

Pendidikan yang bermutu tentunya tidak dengan sendirinya akan hadir dalam setiap jenjang pendidikan, sehingga dalam menjamin mutu pendidikan pada sebuah sekolah harus ada yang namanya penjaminan mutu internal dan penjaminan mutu eksternal (Iskandar, 2017). Penjaminan mutu internal dapat dilakukan langsung oleh sebuah institusi pendidikan dengan cara evaluasi diri dan lain sebagainya. Sedangkan penjaminan mutu eksternal pada sebuah sekolah/madrasah akan dilakukan dengan sebuah system yang dikenal dengan istilah akreditasi.

Akreditasi merupakan kegiatan penilaian kelayakan program dalam satuan pendidikan berdasarkan kriteria yang telah ditetapkan (Awaludin, 2017; Khojah \& Shousha, 2020). Pada pelaksanaannya akreditasi ini untuk tingkat sekolah dasar dan sekolah menengah dibawah naungan Badan Akreditasi 
Nasional Sekolah/ Madrasah (BAN S/M) (Marjuki, et al., 2018).

Tujuan dan manfaat akreditasi itu sendiri bagi sekolah/madrasah diantaranya adalah dapat memberikan informasi tentang kelayakan sekolah/madrasah atau program yang dilaksanakannya berdasarkan SN, memetakan mutu pendidikan berdasarkan SNP dan sebagai acuan dalam upaya peningkatan mutu dan rencana pengembangan sekolah/madrasah (Asopwan, 2018). Sesuai tujuan dan manfaat akreditasi tersebut, tentunya bisa dipetakan problematika apa yang sebenarnya dihadapi oleh sebuah sekolah/madrasah, terutama tentang mutu sekolah/madrasah tersebut yang terkait dengan pemenuhan 8 Standar Nasional Pendidikan (SNP) (Karyanto, et al., 2015).

Awaludin (2017) menjelaskan dalam penelitiannya, bahwa pelaksanaan akreditasi diharapkan dapat mendorong atau menciptakan suasana kondusif bagi pertumbuhan pendidikan dan memberikan arahan untuk evaluasi diri yang berkelanjutan, serta sebagai perangsang untuk terus berusaha mencapai mutu yang diharapkan, sehingga secara tidak langsung dapat menjamin mutu pendidikan (Zulkifli, 2015). Tindak lanjut untuk meningkatkan mutu sekolah, hasil dan rekomendasi akreditasi yang didapat dijadikan bahan pertimbangan oleh sekolah dalam rangka pembuatan kebijakan untuk peningkatan mutu sekolah, serta meningkatkan sarana dan prasarana sekolah (Adha, et al., 2018).

Berangkat dari hal tersebut di atas, selanjutnya peneliti tertarik untuk mengkaji lebih mendalam tentang problematika atau permasalahan apa yang sebenarnya dihadapi oleh sekolah/madrasah dalam meningkatkan mutu pendidikan itu sendiri yang dilihat dan akan dianalis dari hasil akreditasi sekolah/madrasah khususnya tingkat SD/MI se Kabupaten Kuantan Singingi pada tahun 2019.

\section{METODE PENELITIAN}

Dalam penelitian ini penulis menggunakan penelitian deskriptif kualitatif. Adapun metode dan teknik yang digunakan dalam pengumpulan dan pengolahan data adalah dengan dokumentasi, wawancara, dan observasi. Jenis data yang digunakan dalam penelitian ini adalah berupa data primer dan data sekunder, data primer didapatkan dari perolehan akreditasi Sekolah/Madrasah yang dikeluarkan oleh Badan Akreditasi Nasional Sekolah/Madrasah (BAN-S/M) pada tahun 2019, dan data sekunder berupa hasil wawancara dengan informan yang terkait akreditasi serta hasil observasi yang dilakukan oleh penulis di lapangan.

Sedangkan subjek dalam penelitian ini adalah sekolah/madrasah tingkat SD/MI Kabupaten Kuantan Singingi yang diakreditasi pada tahun 2019 yang berjumlah 97 sekolah/madrasah, 95 Sekolah Dasar (SD) yang berada di bawah naungan Kementerian Pendidikan dan Kebudayaan dan 5 Madrasah Ibtidaiyah (MI) yang berada di bawah naungan Kementerian Agama. Teknik analisis data yang digunakan adalah dengan cara menganalisis keseluruhan data yang ada dan digambarkan secara kualitatif untuk memperoleh data yang tepat dan akurat. 


\section{HASIL DAN PEMBAHASAN}

Untuk melihat dan mengetahui problematika mutu sekolah/madrasah berdasarkan hasil akreditasi Sekolah/Madrasah Tingkat SD/MI di Kabupaten Kuatan Singingi yang divisitasi Tahun 2019 terdiri dari 97 Sekolah/Madrasah dengan rincian 5 Madrasah Ibtidaiyah dan 92 Sekolah Dasar, maka dapat diperhatikan tabel berikut ini:

Tabel 1 : Rekapitulasi Hasil Akreditasi Sekolah/Madrasah Tingkat SD/MI Kabupaten Kuantan Singingi Tahun 2019

\begin{tabular}{|c|c|c|c|c|c|c|c|c|c|c|c|}
\hline \multirow{2}{*}{$\begin{array}{c}\mathbf{N} \\
\mathbf{0}\end{array}$} & \multirow[t]{2}{*}{ Standar/Komponen } & \multicolumn{2}{|c|}{$\begin{array}{c}<60 \\
\text { (Sangat Kurang) }\end{array}$} & \multicolumn{2}{|c|}{$\begin{array}{c}61-70 \\
\text { (Kurang) }\end{array}$} & \multicolumn{2}{|c|}{$\begin{array}{c}71-80 \\
\text { (Cukup) }\end{array}$} & \multicolumn{2}{|c|}{$\begin{array}{l}81-90 \\
\text { (Baik) }\end{array}$} & \multicolumn{2}{|c|}{$\begin{array}{c}91 \text { - } 100 \\
\text { (Anggul) }\end{array}$} \\
\hline & & $\mathbf{F}$ & $\%$ & $\mathbf{F}$ & $\%$ & $\mathbf{F}$ & $\%$ & $\mathbf{F}$ & $\%$ & $\mathbf{F}$ & $\%$ \\
\hline 1 & Standar Isi & 0 & $0 \%$ & 1 & $1 \%$ & 2 & $2 \%$ & 37 & $38 \%$ & 57 & $59 \%$ \\
\hline 2 & Standar Proses & 0 & $0 \%$ & 2 & $2 \%$ & 10 & $10 \%$ & 43 & $44 \%$ & 42 & $43 \%$ \\
\hline 3 & Standar Kompetensi Lulusan & 0 & $0 \%$ & 2 & $2 \%$ & 5 & $5 \%$ & 58 & $60 \%$ & 32 & $33 \%$ \\
\hline 4 & Standar Pendidik dan Tendik & 1 & $1 \%$ & 6 & $6 \%$ & 48 & $50 \%$ & 37 & $38 \%$ & 5 & $5 \%$ \\
\hline 5 & Standar Sarana dan Prasarana & 1 & $1 \%$ & 18 & $19 \%$ & 38 & $39 \%$ & 32 & $33 \%$ & 8 & $8 \%$ \\
\hline 6 & Standar Pengelolaan & 1 & $1 \%$ & 2 & $2 \%$ & 13 & $13 \%$ & 43 & $44 \%$ & 38 & $39 \%$ \\
\hline 7 & Standar Pembiayaan & 0 & $0 \%$ & 1 & $1 \%$ & 4 & $4 \%$ & 25 & $26 \%$ & 67 & $69 \%$ \\
\hline 8 & Standar Penilaian & 2 & $2 \%$ & 1 & $1 \%$ & 7 & $7 \%$ & 42 & $43 \%$ & 45 & $46 \%$ \\
\hline
\end{tabular}

Sumber: BAN S/M tentang Hasil Akreditasi S/M Tahun 2019

Berdasarkan tabel di atas dapat diuraikan beberapa hal terkait perolehan skor akreditasi perkomponen/standar sekolah/madrasah tingkat SD/MI sebagai berikut:

1. Pada indikator pertama yaitu standar isi sebanyak 1 sekolah/madrasah memperoleh nilai kurang, 2 sekolah/madrasah memperoleh nilai cukup, 37 sekolah/madrasah memperoleh nilai baik, dan 57 sekolah madrasah memperoleh nilai unggul.

2. Pada indikator kedua yaitu standar proses sebanyak 2 sekolah/madrasah memperoleh nilai kurang, 10 sekolah/madrasah memperoleh nilai cukup, 43 sekolah/madrasah memperoleh nilai baik, dan 42 sekolah madrasah memperoleh nilai unggul.

3. Pada indikator ketiga yaitu standar kompetensi lulusan sebanyak 2 sekolah/madrasah memperoleh nilai kurang, 5 sekolah/madrasah memperoleh nilai cukup, 58 sekolah/madrasah memperoleh nilai baik, dan 32 sekolah madrasah memperoleh nilai unggul.

4. Pada indikator keempat yaitu standar tenaga pendidik dan tenaga kependidikan sebanyak 1 sekolah/madrasah memperoleh nilai sangat kurang, 6 sekolah/madrasah memperoleh nilai kurang, 48 sekolah/madrasah memperoleh nilai cukup, 5 sekolah/madrasah memperoleh nilai baik, dan 57 sekolah madrasah memperoleh nilai unggul.

5. Pada indikator kelima yaitu standar sarana dan prasarana sebanyak 1 sekolah/madrasah memperoleh nilai sangat kurang, 18 sekolah/madrasah memperoleh nilai kurang, 38 sekolah/madrasah memperoleh nilai cukup, 
32 sekolah/madrasah memperoleh nilai baik, dan 8 sekolah madrasah memperoleh nilai unggul.

6. Pada indikator keenam yaitu standar pengelolaan sebanyak 1 sekolah/madrasah memperoleh nilai sangat kurang, 2 sekolah/madrasah memperoleh nilai kurang, 13 sekolah/madrasah memperoleh nilai cukup, 43 sekolah/madrasah memperoleh nilai baik, dan 38 sekolah madrasah memperoleh nilai unggul.

7. Pada indikator ketujuh yaitu standar pembiayaan pendidikan isi sebanyak 1 sekolah/madrasah memperoleh nilai kurang, 4 sekolah/madrasah memperoleh nilai cukup, 25 sekolah/madrasah memperoleh nilai baik, dan 67 sekolah madrasah memperoleh nilai unggul.

8. Pada indikator kedelapan yaitu standar penilaian pendidikan sebanyak 2 sekolah/madrasah memperoleh nilai sangat kurang, 1 sekolah/madrasah memperoleh nilai kurang, 7 sekolah/madrasah memperoleh nilai cukup, 42 sekolah/madrasah memperoleh nilai baik, dan 45 sekolah madrasah memperoleh nilai unggul.

Analisis pada data 97 sekolah/madrasah yang menjadi sampel dalam penelitian ini yang terdiri dari 5 Madrasah Ibtidaiyah (MI) dan 92 Sekolah Dasar (SD) diketahui problematika utama yang dihadapi sekolah/madrasah berdasarkan hasil capaian akreditasi tahun 2019 di Kabupaten Kuantan Singingi sebagai berikut;

Pertama, standar yang keempat yakni standar pendidik dan tenaga kependidikan, ini terlihat bahwa dari 97 sekolah/madrasah tingkat SD/MI hanya 5 (5\%) sekolah/madrasah yang memperoleh nilai unggul, 37 (38\%) sekolah/madrasah yang memperoleh nilai baik, selebihnya baru dalam kategori cukup yakni 48 (50\%), 6 (6\%) pada ketegori kurang dan 1 (1\%) sekolah/madrasah pada kategori sangat kurang.

Kedua, standar yang kelima yakni standar sarana dan prasarana pendidikan, ini terlihat bahwa dari 97 sekolah/madrasah untuk tingkat SD/MI hanya $5(5 \%)$ sekolah/madrasah yang memperoleh nilai unggul, 37 (38\%) sekolah/madrasah yang memperoleh nilai baik, selebihnya baru dalam kategori cukup yakni 48 (50\%), 6 (6\%) pada ketegori kurang dan 1 (1\%) sekolah/madrasah pada kategori sangat kurang.

Hal tersebut di atas, juga didukung oleh hasil wawancara penulis dengan salah Nopyanti (2019) yang telah melaksanakan visitasi akreditasi ke beberapa sekolah/madrasah di Kabupaten Kuantan Singingi mengatakan bahwa temuan utama di lapangan terkait pemenuhan kebutuhan atau mutu sekolah/ madrasah berdasarkan 8 standar nasional pendidikan adalah pada standar keempat dan standar kelima yakni standar pendidik dan tenaga kependidikan, dan standar sarana dan prasarana. Dari beberapa sekolah/madrasah yang divisit ditemukan permasalahan terkait dengan dua pemenuhan standar tersebut seperti kualifikasi akademik tenaga pendidik, kepemilikan sertifikat pendidik, kesesuaian guru mengajar dengan latar belakang pendidikannya serta ketercukupan tenaga kependidikannya untuk standar pendidik dan tenaga kependidikan, serta ketersediaan dan ketercukupan ruang guru, ruang perpustakaan, ruang UKS, ruang sirkulasi, 
kepemilikan kantin, dan alat peraga pembelajaran pada standar sarana dan prasarana.

Pernyataan yang senada juga disampaikan oleh salah seorang kepala sekolah dasar yang ada di Kabupaten Kuantan Singingi, Dahlan (2019) yang mengatakan bahwa dari 8 standar nasional pendidikan yang menjadi indikator penilaian akreditasi permasalahan utama yang dihadapi sekolahnya adalah pemenuhan standar pendidik dan tenaga kependidikan serta standar sarana dan prasarana yang mana sekolah yang menjadi tempat tugasnya hanya memperoleh nilai pada kategori kurang (D) dengan rentang nilai antara $61 \leq$ NA $\leq 70$ untuk standar pendidik dan tenaga kependidikan dan kategori cukup (C) dengan rentang nilai antara $(71 \leq \mathrm{NA} \leq 80)$ untuk standar sarana dan prasarana.

Begitu juga dengan temuan hasil observasi penulis di lapangan untuk dalam melaksanakan visitasi akreditasi. Pada dasarnya secara umum sekolah/madrasah mengalami problematika dalam pemenuhan standar pendidik dan tenaga kependidikan dan standar sarana dan prasarana. Indikatornya seperti kualifikasi akademik tenaga pendidik, kepemilikan sertifikat pendidik, kesesuaian guru mengajar dengan latar belakang pendidikannya serta ketercukupan tenaga kependidikannya untuk standar pendidik dan tenaga kependidikan. Sedangkan untuk standar sarana dan prasarana secara umum sekolah/madrasah terkendala dengan pemenuhan indikator tentang ruang guru, ruang perpustakaan, ruang UKS, ruang sirkulasi, kepemilikan kantin, dan alat peraga pembelajaran.

Dari beberapa temuan di lapangan, problematika mutu yang dihadapi oleh sekolah/madrasah itu apa. Problematika yang dimaksud disini adalah berasal dari kata problema, yang berasal dari Bahasa Inggris yaitu "problematic" yang artinya persoalan atau masalah. Sementara dalam Kamus Besar Bahasa Indonesia dikatakan bahwa problema adalah hal yang belum dapat dipecahkan; yang menimbulkan permasalahan. Masalah “adalah suatu kendala atau persoalan yang harus dipecahkan dengan kata lain masalah merupakan kesenjangan antara kenyataan dengan suatu yang diharapkan dengan baik, agar tercapai hasil yang maksimal". Jadi Problematika adalah suatu kesenjangan antara teori atau harapan dengan fakta dan kenyataan di lapangan yang membutuhkan penyelesaian atau pemecahan (Muhith, 2018).

Pengembangan mutu dalam sektor pendidikan sesungguhnya mengadopsi berbagai konsep walaupun yang paling dominan adalah konsep mutu dalam dunia industri (Jabbar \& Hussin, 2019). Akan tetapi, pengembangan mutu akhirnya digunakan di ranah pendidikan menjadi suatu konsep yang "paten", sehingga mutu pendidikan merupakan suatu hal yang menjelma menjadi kebutuhan primer bagi sekolah untuk bersaing dengan sekolah-sekolah lainnya (Tardian, 2019).

Ada 3 komponen mutu yang perlu menjadi perhatian bersama yakni: (1) mampu memenuhi keinginan pelanggan; (2) memfokuskan pada produk yang dihasilkan dan kepuasan layanan; dan (3) terus menyesuaikan dengan tuntutan perubahan yang ada karena terus bergerak secara dinamis untuk mampu menjaga kepuasaan pelanggan (Darmaji et al., 2019). 
Dalam perspektif total qualiy management, pelanggan adalah raja. Konsep ini berbicara tentang bagaimana memberikan sesuatu yang diinginkan oleh pelanggan dalam pendidikan, serta kapan dan bagaimana mereka menginginkannya. Hal ini disesuaikan dengan harapan dan gaya pelanggan dengan cara mengemas hasil produksi dan jasa yang sesuai dengan kebutuhan mereka (Suhermanto \& Anshari, 2018). Melalui hal tersebut, dapat dipastikan dipastikan bahwa pelanggan akan kembali lagi dan memberitahu temantemannya tentang hasil produksi atau layanan tersebut (Hamid, 2010). Hal yang harus dipahami adalah; persepsi dan harapan pelanggan tersebut sifatnya tidak absolut dan berubah-ubah sesuai dengan perkembangan ilmu pengetahuan, tekhnologi,sosial, budaya dan politik yang mengitarinya (Amir, 2019).

Mutu madrasah merupakan sesuatu yang absolut dan harus dipertahankan serta dilestarikan (Kurniawan, 2017), dijadikan sebuah budaya, sehingga kualitas madrasah terjamin. Menurut Garvin sebagaimana dikutip Said (2018), terdapat lima macam perspektif mutu yaitu; transcendental approach, product based approach, use based approach, manufacturing based approach, and value based approach.

Berbicara masalah mutu pendidikan ini pemerintah sudah mengatur masalah standar pendidikan itu sendiri. Standar pendidikan dikembangkan dan ditetapkan untuk mengukur/ mengevaluasi/menilai mutu pendidikan, hasilnya sebagai acuan untuk menyusun program peningkatan mutu pendidikan. Dalam UU Nomor 20 Tahun 2003 tentang Sistem Pendidikan Nasional (Sisdiknas) dikatakan bahwa Standar Nasional Pendidikan (SNP) adalah kriteria minimal sekolah di Indonesia.

Untuk mengukur ketercapaian standar tersebut, maka sebuah lembaga pendidikan harus menerapkan Sistem Penjaminan Mutu Internal (SPMI) dan Sistem Penjaminan Mutu Eksternal (SPME). SPMI dapat dilakukan oleh sekolah/madrasah itu sendiri secara internal seperti adanya pembentukan Gugus Kendali Mutu (GKM) (Sridana et al., 2018). Sedangkan untuk SPME sekolah/madrasah di Indonesia akan diakreditasi oleh sebuah badan yang dinamakan dengan Badan Akreditasi Nasional Sekolah/Madrasah (BAN-SM). Dari hasil akreditasi yang dilakukan oleh BAN-SM ini tentunya diharapkan agar tergambar mutu pendidikan yang ada di Indonesia, dari gambaran mutu ini secara implisit juga akan tergambar problematika-problematika atau permasalahan-permasalahan yang dihadapi oleh lembaga pendidikan terkait dengan mutu sekolah terutama tentang pencapaian standar nasional pendidikan itu sendiri yang terdiri dari delapan standar.

Akreditasi adalah kegiatan penilaian kelayakan program dan/atau satuan pendidikan berdasarkan kriteria yang telah ditetapkan sebagaimana dinyatakan pada UU Nomor 20 Tahun 2003 tentang Sistem Pendidikan Nasional, pasal 1 ayat (22). Akreditasi sekolah/madrasah adalah proses penilaian secara komprehensif terhadap kelayakan satuan atau program pendidikan, yang hasilnya diwujudkan dalam bentuk pengakuan danperingkat kelayakandalam bentuk yang diterbitkanoleh suatu lembaga yang mandiri dan professional (Malik et al., 2018). 
Akreditasi juga didefenisikan sebagai kegiatan penilaian kelayakan program dalam satuan pendidikan berdasarkan kriteria yang telah ditetapkan. Akreditasi sekolah merupakan kegiatan penilaian yang dilakukan oleh pemerintah dan/atau lembaga mandiri yang berwenang untuk menentukan kelayakan program dan/atau satuan pendidikan pada jalur pendidikan formal dan nonformal pada setiap jenjang dan jenis pendidikan, berdasarkan kriteria yang telah ditetapkan, sebagai bentuk akuntabilitas publik yang dilakukan secara objektif, adil, transparan, dan komprehensif dengan menggunakan instrumen dan kriteria yang mengacu kepada Standar Nasional Pendidikan.

Akreditasi marupakan suatu penilaian yang dilakukan oleh pemerintah terhadap sekolah swasta untuk menentukan peringkat pengakuan pemerintah terhadap sekolah tersebut. Sementara itu juga ada yang mendefenisikan bahwa akreditasi adalah kegiatan penilaian kelayakan program dalam satuan pendidikan berdasarkan kriteria yang telah ditentukan (Herabudin, 2013; Ilyas, 2019).

Berdasarkan beberapa pengertian tersebut di atas akreditasi sekolah dapat diartikan sebagai tindakan menilai tingkat kelayakan setiap sekolah melalui tindakan membandingkan keadaan sekolah menurut kenyataan dengan kriteria yang telah ditetapkan (Ríos, 2015). Jika keadaan sekolah kenyataanya lebih baik atau sama dengan standar, maka sekolah yang bersangkutan dinyatakan terakreditasi. Sebaliknya, sebuah sekolah dinyatakan tidak terakreditasi jika keadaan sekolah/madrasah menurut kenyataanya dibawah standar yang telah ditetapkan. Dengan demikian hasil akreditasi dinyatakan dalam bentuk pengakuan terakreditasi dan tidak terakreditasi.

Dalam pelaksanaan akreditasi, ada beberapa tujuan dan manfaat yang diharapkan selain dapat memetakan mutu pendidikan berdasarkan SNP, bagi kepala sekolah/madrasah, hasil akreditasi diharapkan dapat dijadikan bahan informasi untuk pemetaan indikator kelayakan sekolah/madrasah, kinerja warga sekolah/madrasah, termasuk kinerja kepala sekolah/madrasah selama periode kepemimpinannya (Buzdar, et al., 2018). Di samping itu, hasil akreditasi juga diperlukan kepala sekolah/madrasah sebagai bahan masukan untuk penyusunan program serta anggaran pendapatan dan belanja sekolah/madrasah (Fitrah, 2017). Bagi guru, hasil akreditasi merupakan dorongan untuk selalu meningkatkan diri dan bekerja keras dalam memberikan layanan terbaik bagi peserta didik guna mempertahankan dan meningkatkan mutu sekolah/madrasah. Secara moral, guru senang bekerja di sekolah/madrasah yang diakui sebagai sekolah/madrasah bermutu. Sementara bagi pemerintah hasil akreditasi dapat dijadikan sebagai bahan pertimbangan dalam menyusun kebijakan peningkatan mutu pendidikan nasional (Malik et al., 2018).

Berdasarkan pemaparan hasil penelitian dan pembahasan di atas terutama tujuan dan manfaat dari pelaksanaan akreditasi tersebut, kita dapat mengetahui bahwasahnya akreditasi sekolah/madrasah tidak saja bertujuan dan memberikan manfaat untuk pihak sekolah/madrasah saja, akan tetapi juga memberikan manfaat bagi seluruh stakeholder bidang pendidikan, baik bagi kepala sekolah, guru, orang tua, peserta didik maupun pihak pemerintah. 
Diantara tujuan dan manfaat yang bisa dirasakan oleh seluruh stakeholder pendidikan terutama pihak sekolah adalah diketahuinya permasalahanpermasalahan utama yang dihadapi sekolah itu sendiri atau dengan kata lain dari hasil capaian akreditasi yang diperoleh sekolah/madrasah akan terlihat problematika mutu yang dihadapi sesuai dengan 8 Standar Nasional Pendidikan (SNP) yang tertuang dalam UU Nomor 20 Tahun 2003.

Sebagaimana telah dipaparkan di atas, dari hasil analisis data perolehan akreditasi sekolah/madrasah untuk tingkat SD/MI di Kabupaten Kuantan Singingi tahun 2019 dan didukung oleh hasil wawancara dengan asesor BANS/M dan kepala sekolah dasar yang telah melaksanakan akreditasi serta hasil observasi langsung yang dilakukan di lapangan, dapat disimpulkan bahwa problematika utama yang dihadapi oleh sekolah/madrasah khususnya tingkat SD/MI di Kabupaten Kuantan Singingi adalah terkait pemenuhan standar pendidik dan tenaga kependidikan, dan standar sarana prasarana. Dalam pemenuhan standar pendidik dan tenaga kependidikan yang menjadi indikator permasalahannya adalah terkait kualifikasi akademik tenaga pendidik, kepemilikan sertifikat pendidik, kesesuaian guru mengajar dengan latar belakang pendidikannya serta ketercukupan tenaga kependidikannya. Sementara untuk pemenuhan standar sarana dan prasarana terkait kelengkapan sarana dan prasarana seperti: ruang guru, ruang perpustakaan, ruang UKS, ruang sirkulasi, kepemilikan kantin, dan alat peraga pembelajaran.

\section{KESIMPULAN}

Berdasarkan hasil penelitian dan pembahasan di atas, maka dapat disimpulkan bahwa problematika mutu yang dihadapi oleh sekolah/madrasah pada tingkat SD/MI di Kabupaten Kuantan Singingi berdasarkan hasil akreditasi tahun 2019 adalah; pertama, pemenuhan standar pendidik dan tenaga kependidikan, diantaranya terkait kualifikasi akademik tenaga pendidik, kepemilikan sertifikat pendidik, kesesuaian guru mengajar dengan latar belakang pendidikannya serta ketercukupan tenaga kependidikannya; kedua, pemenuhan standar sarana dan prasarana yang memadai, diantaranya terkait kelengkapan sarana dan prasarana, seperti ruang guru, ruang perpustakaan, ruang UKS, ruang sirkulasi, kepemilikan kantin, dan alat peraga pembelajaran.

Penelitian ini memberikan implikasi pada pentingnya pembuatan kebijakan pemerintah yang didasarkan pada hasil analisis nilai akreditasi BAN$\mathrm{S} / \mathrm{M}$, sehingga mampu meningkatkan mutu pendidikan di daerah. Melalui hal tersebut, akan memberikan kesempatan bagi para peneliti selanjutnya, untuk mengkaji lebih mendalam tentang strategi yang dapat dilakukan oleh sekolah/madrasah dalam meningkatkan mutu pendidikannya. 


\section{DAFTAR PUSTAKA}

Aarti, C. (2015). The Effectiveness of Total Quality Management in The Manufacturing Industries. International Journal of Management, IT and Engineering, 5(10), 210-225.

Adha, M. A., Benyamin, C., Octaviarnis, I., \& Thalib, D. (2018). Peran Akreditasi dalam Penjaminan Mutu Pendidikan di Sekolah Dasar. Media Manajemen Pendidikan, 2(2), 270-278. https:// doi.org/10.30738/mmp.v2i2.5780

Agrawal, N. M. (2019). Modeling Deming's Quality Principles to Improve Performance using Interpretive Structural Modeling and MICMAC Analysis. International Journal of Quality and Reliability Management, 36(7), 1159-1180. https://doi.org/10.1108/IJQRM-07-2018-0204

Amai, S. (2018). Proses Pengambilan Keputusan untuk Mengembangkan Mutu Madrasah Proses Pengambilan Keputusan untuk Mengembangkan Mutu Madrasah. Jurnal Manajemen Pendidikan, 8(1), 37-56. https://doi.org/10.21580/nw.2014.8.1.569

Amir. (2019). Membangun Budaya Mutu Pada Lembaga Pendidikan Islam Menuju Madrasah Unggul. Al-Tanzim: Jurnal Manajemen Pendidikan Islam, 3(2), 1-12. https:/ / doi.org/10.33650/al-tanzim.v3i2.676

Amir, F. (2015). Developing Structure for Management of Quality in Schools: Steps towards Quality Assurance Systems. American Journal of Educational Research, 3(8), 977-981. https:/ / doi.org/10.12691/education-3-8-5

Ariyani, E. S. (2015). Penerapan Sistem Manajemen Mutu ISO 9001:2008 sebagai Upaya Peningkatan Mutu Layanan SD IT Bias Assalam Kota Tegal. Journal of Elementary Education, 4(1), 7-12.

Asopwan, D. (2018). Studi Tentang Akreditasi Dalam Meningkatkan Produktivitas Sekolah. Indonesian Journal of Education Management and Administration Review, 2(2), 264-271.

Awaludin, A. A. R. (2017). Akreditasi Sekolah Sebagai Suatu Upaya Penjaminan Mutu Pendidikan di Indonesia. Jurnal SAP, 2(1), 12-21. https://doi.org/10.1017/CBO9781107415324.004

Buzdar, M. A., Jalal, H., \& Mohsin, M. N. (2018). Gaps between Acquired and Required Teacher Education Graduate Attributes: Does Accreditation Influence in Pakistan? Eurasian Journal of Educational Research, 76, 113122. https://doi.org/10.14689/ejer.2018.76.6

Chairunnisa, C. (2016). Manajemen Pendidikan dalam Multi Perspektif. Jakarta: PT. Raja Grafindo Persada.

Crosby, A., Pham, K., Peterson, J. F., \& Lee, T. (2020). Digital Work Practices: Affordances in Design Education. International Journal of Art and Design Education, 39(1), 22-37. https:/ / doi.org/10.1111/jade.12231

Darmaji, Supriyanto, A., \& Timan, A. (2019). Sistem Penjaminan Mutu Internal Sekolah untuk Meningkatkan Mutu Lulusan. JMSP (Jurnal Manajemen dan Supervisi Pendidikan), 3(3), 130-137. 
Dudin, M. N., Smirnova, O. O., Vysotskaya, N. V., Frolova, E. E., \& Vilkova, N. G. (2017). The Deming Cycle (PDCA) Concept as a Tool for The Transition to The Innovative Path of The Continuous Quality Improvement in Production Processes of The Agro-Industrial Sector. European Research Studies Journal, 20(2), 283-293.

Fitrah, M. (2017). Peran Kepala Sekolah dalam Meningkatkan Mutu Pendidikan. Jurnal Penjaminan Mutu, 3(1), 31-42.

Hamid, A. (2010). Aplikasi Tatal Quality Management (TQM) Pendidikan Tinggi dalam Rangka Pelayanan Pelanggan Mahasiswa Asing di UIIM. Jurnal Manajemen Pendidikan, 1(2), 130-140.

Ilyas, M. (2019). Determining Critical Success Factors for Quality and Accreditation through Delphi Technique. International Journal of Higher Education, 8(3), 148-158. https://doi.org/10.5430/ijhe.v8n3p148

Iskandar. (2017). Improving the Quality of Academic Services through Implementation of Internal Quality Assurance System in State Institute of Islamic Studies STS Jambi. Journal of Education and Practice, 8(3), 57-63.

Jabbar, M. N., \& Hussin, F. (2019). Quality Management as a Strategic Tool to Enhance The Relationship Between Leaders' Behavior and Lecturers' Job Satisfaction. International Journal of Higher Education, 8(3), 36-46. https://doi.org/10.5430/ijhe.v8n3p36

Karyanto, U. G., Rahman, A., \& Darwin, D. (2015). Implikasi Akreditasi Sekolah Terhadap Peningkatan Mutu Tata Kelola SMK Negeri 1 Oku. Jurnal Manajemen Pendidikan Indonesia, 7(2), 43-57.

Khojah, A., \& Shousha, A. (2020). Academic Accreditation Process of English Language Institute: Challenges and Rewards. Higher Education Studies, 10(2), 176-188. https://doi.org/10.5539/hes.v10n2p176

Komariah, A., \& Engkoswara. (2017). Administrasi Pendidikan. Bandung: Alfabeta.

Kurniawan, S. (2017). Pengembangan Manajemen Mutu Pendidikan Islam di Madrasah. Al-Tanzim: Jurnal Manajemen Pendidikan Islam, 1(2), 25-36. https:/ / doi.org/10.33650/al-tanzim.v1i2.111

Malik, A., Nyoto, A., Arismunandar, Susetyo, B., \& Anjaya, C. (2018). Pedoman Akreditasi Sekolah/Madrasah. Jakarta: Badan Akreditasi Nasional Sekolah/Madrasah.

Marjuki, Mardapi, D., \& Kartowagiran, B. (2018). Pengembangan Model Akreditasi Sekolah Menengah Atas/Madrasah Aliyah (SMA/MA). Jurnal Penelitian dan Evaluasi Pendidikan, 22(1), 105-117.

Muhith, A. (2018). Problematika Pembelajaran Tematik Terpadu di MIN III Bondowoso. Indonesian Journal of Islamic Teaching, 1(1), 45-61.

Ríos, C. (2015). Quality Assurance in Higher Education in Spain: An Overview of the Accreditation System. International Research and Review: Journal of Phi Beta Delta, 5(1), 25-45.

Said, A. (2018). Kepemimpinan Kepala Sekolah dalam Melestarikan Budaya Mutu Sekolah. Evaluasi, 2(1), 257-273. 
Satria, R., Supriyanto, A., Timan, A., \& Adha, M. A. (2019). Peningkatan mutu sekolah melalui manajemen hubungan masyarakat. Jurnal Akuntabilitas Manajemen Pendidikan, $7(2)$, 199-207. https://doi.org/10.21831/amp.v7i2.26018

Sridana, N., Wilian, S., \& Setiadi, D. (2018). Sistem Penjaminan Mutu Internal di Satuan Pendidikan Menengah (SMA). Jurnal Pengabdian Magister Pendidikan IPA, 1(1), 45-51. https:// doi.org/10.29303/jpmpi.v1i1.212

Suhermanto, S., \& Anshari, A. (2018). Implementasi TQM terhadap Mutu Institusi dalam Lembaga Pendidikan. Al-Tanzim: Jurnal Manajemen Pendidikan Islam, 2(1), 107-113. https://doi.org/10.33650/altanzim.v2i1.259

Sutarto. (2015). Manajemen Mutu Terpadu (MMT-TQM): Teori dan Penerapan di Lembaga Pendidikan. Yogyakarta: UNY Press.

Tardian, A. (2019). Manajemen Strategik Mutu Sekolah: Studi Kasus di SD AlIrsyad Al Islamiyyah 02 Purwokerto. Jurnal Kependidikan, 7(2), 192-203.

Zulkifli. (2015). Kinerja Badan Akreditasi Provinsi Sekolah/Madrasah (BAP S/M) Dalam Meningkatkan Mutu Pendidikan di Provinsi Sulawesi Tenggara. Jurnal Al-Ta'dib, 8(2), 168-190. 